\title{
ART access-related barriers faced by HIV-positive persons linked to care in southern Ghana: a mixed method study
}

Augustine Ankomah¹, John Kuumuori Ganle ${ }^{1}$, Margaret Yaa Lartey ${ }^{2}$, Awewura Kwara ${ }^{3}$, Priscilla Awo Nortey ${ }^{4}$, Michael Perry Kweku Okyerefo ${ }^{5}$ and Amos Kankponang Laar ${ }^{1 *}$

\begin{abstract}
Background: Timely and enduring access to antiretroviral therapy (ART) by HIV-infected individuals has been shown to substantially reduce HIV transmission risk, HIV-related morbidity and mortality. However, there is evidence that in addition to limited supply of antiretrovirals (ARVs) and linkage to ART in many low-income countries, HIV+ persons often encounter barriers in accessing ART-related services even in contexts where these services are freely available. In Ghana, limited research evidence exists regarding the barriers HIV+ persons already linked to ART face. This paper explores ART access-related barriers that HIV+ persons linked to care in southern Ghana face.

Methods: A mixed method study design, involving a cross-sectional survey and qualitative in-depth interviews, was conducted to collect data from four healthcare providers and a total of 540 adult HIV+ persons receiving ART at four treatment centres in Ghana. We used univariate analysis to generate descriptive tabulations for key variables from the survey. Data from qualitative in-depth interviews were thematically analysed. Results from the survey and in-depth interviews were brought together to illuminate the challenges of the HIV+ persons.
\end{abstract}

Results: All (100\%) the HIV+ persons interviewed were ARV-exposed and linked to ART. Reasons for taking ARVs ranged from beliefs that they will suppress the HIV virus, desire to maintain good health and prolong life, and desire to prevent infection in unborn children, desire both to avoid death and to become good therapeutic citizens (abide by doctors' advice). Despite this, more than half of the study participants (63.3\%) reported seven major factors as barriers hindering access to ART. These were high financial costs associated with accessing and receiving ART (26\%), delays associated with receiving care from treatment centres (24\%), shortage of drugs and other commodities (23\%), stigma (8.8\%), fear of side effects of taking ARVs (7.9\%), job insecurity arising from regular leave of absence to receive ART (5.3\%), and long distance to treatment centres (4.9\%).

Conclusions: The results in this study suggest that efforts to provide and scale-up ART to all HIV+ persons must be accompanied by interventions that address structural and individual level access barriers.

Keywords: HIV, AIDS, PLH, Antiretrovirals, Antiretroviral therapy, Access, Barriers, Ghana

\footnotetext{
* Correspondence: alaar@ug.edu.gh

'Department of Population, Family and Reproductive Health, School of

Public Health, University of Ghana, Legon, Accra, Ghana

Full list of author information is available at the end of the article
}

(c) The Author(s). 2016 Open Access This article is distributed under the terms of the Creative Commons Attribution 4.0 International License (http://creativecommons.org/licenses/by/4.0/), which permits unrestricted use, distribution, and reproduction in any medium, provided you give appropriate credit to the original author(s) and the source, provide a link to the Creative Commons license, and indicate if changes were made. The Creative Commons Public Domain Dedication waiver (http://creativecommons.org/publicdomain/zero/1.0/) applies to the data made available in this article, unless otherwise stated. 


\section{Background}

Globally, timely access to antiretrovirals (ARVs) and antiretroviral therapy (ART) by people living with HIV (PLH) has been shown to substantially reduce morbidity and mortality, reduce HIV transmission risk even with modest ART coverage of the HIV-infected population and imperfect ART adherence, improve employment rates to levels prior to HIV infection, as well as improve the overall quality of life of PLH [1-5]. Indeed, one recent report detailed the benefits of ART as follows: ART averted 5.5 million deaths in low- and middle-income countries between 1995 and 2012, with Sub-Saharan Africa accounting for most of those lives saved; ART reduced the risk of HIV transmission by up to $96 \%$ and the risk of tuberculosis infection among PLH by 65\% [6]. Also, spending on ART generated economic returns of double or more than the initial investment, while workingage adults living with HIV can return to work earlier when they receive treatment, boosting labour productivity and reducing hardship among affected households [6].

These benefits notwithstanding, durable access to ART remains a crucial problem for PLH in resources-limited settings, and studies continue to highlight the challenges in ensuring effective HIV continuum of care (i.e. Proportion who know their diagnosis of HIV, of them how many engaged in HIV care, of them how many prescribed ART, retained on ART, and of them proportion with viral load undetectable) [4-7]. There is evidence that in addition to limited supply of ARVs and ART in many low-income countries, PLH often encounter challenges in accessing ARVs and ART services even in contexts where these services are freely available [4-7]. For example, although the number of people receiving ART continues to rise in Africa, it is estimated that approximately three-quarters of adults living with HIV in sub-Saharan Africa have no access to ART $[6,8]$. Of the 21.2 million people in Africa eligible for ART in 2013 based on the 2013 WHO guidelines for example, only 7.6 million people were receiving HIV treatment [6]. In the case of Ghana, ART for PLH was piloted in June 2003 [9]. The Ghana National HIV/ STI Control Programme of the Ghana Health Service reported that by December 2007, only about 13,429 out of an estimated 70,000 HIV+ persons who needed ART had been put on treatment [10]. As at November 2009 the number of $\mathrm{HIV}+$ persons who were receiving ART rose to about 31,400 [11]. Despite this laudable achievement in Ghana, about $70 \%$ of PLHIV in need of ART did not have access in 2009 [11].

Gaps in testing, delays in seeking/accessing treatment and retention are acknowledged weaknesses the HIV prevention-care continuum in Ghana. Successful attainment of treatment cascade steps has not been fully achieved. For example, HIV counseling \& testing in the general adult population remains low, within the range of
4-10\% [11]. Of note, while still lower than the optimal level, counseling and testing among pregnant women is up to $67 \%$ as of 2011 . Despite these gains, about half of eligible people living with HIV received ART in 2011 [11]. However, data on adherence to ART regimens is poor likely due to the difficulties in linking HIV+ persons to treatment as well as retention into care. Reliable estimates on achievement of the key HIV care cascade steps have not been widely reported in Ghana. The corresponding author of this paper and his team are currently implementing a study to understand the barriers as well as facilitators to achieving the HIV treatment and prevention care cascade in Ghana.

In the international research literature, a number of barriers have been identified as hindering access to ART. Limited trained health staff [12-14], lack of comfortable hospital facilities to provide ART $[15,16]$, shortages and unavailability of ART in certain places especially in lowincome settings $[17,18]$, high costs, including travel, opportunity and social costs associated with ART [7, 19], are some of the most commonly cited barriers HIV+ persons face in accessing ART. Fear of side effects [20], fear of stigma and discrimination $[14,21]$ and lack of adequate social support [22] have also been reported as formidable barriers hindering access to ART.

While there is growing recognition in both international and local policy and empirical research literature that PLH may encounter barriers in accessing ART services even in contexts where these services are freely available, there is limited research in Ghana that asks PLH about the barriers that PLH already linked to ART face. For example, one study in Ghana suggested that shortage of ARVs and differential pricing policy between private and public health facilities - the ART services in private health facilities attract a fee of about $\$ 30$ per month, ten times greater than the public rate - hindered access to ART [11]. Another study suggested that long waiting time before care is received in ART clinics discouraged PLH from accessing ART in Ghana [9]. While these pioneering studies in Ghana have highlighted some of the barriers to accessing ART, they nevertheless have not paid sufficient attention to the perspectives of PLH. Understanding the perspectives of PLH in relation to the barriers they face in accessing ART could however form the basis for implementing contextually relevant programmatic initiatives to both redress these challenges and better improve access and adherence to ART [14]. This paper presents and discusses access related barriers that $\mathrm{HIV}+$ persons already linked to ART in southern Ghana face.

\section{Methods}

Study design

This study forms part of a larger original study that was conducted to examine non-prescription drug use among 
$\mathrm{HIV}+$ persons on ART, adherence to ART, and barriers $\mathrm{HIV}+$ persons face accessing ART in Ghana. A mixed method study design, involving a cross-sectional survey and qualitative in-depth interviews, was conducted to collect data from healthcare providers and a total of 540 adult $\mathrm{HIV}+$ persons receiving ART at four treatment centres in the Eastern and Greater Accra regions of Ghana. For the purposes of the current paper, we focus on, and report findings from both the survey and qualitative interviews that are related to the barriers HIV+ persons face accessing ART.

\section{Study sites}

Empirical research was conducted at four health facilities in southern Ghana where ART is offered to HIVinfected clients. These health facilities are the Fevers Unit of the Korle $\mathrm{Bu}$ Teaching Hospital and the Tema General Hospital (both in the Greater Accra region of Ghana), and the Atua Government Hospital, and St Martins de Porres Hospital in the Eastern region of Ghana. The Korle $\mathrm{Bu}$ Teaching Hospital is one of the tertiary hospitals in southern part of Ghana. The Fevers unit is affiliated to the department of medicine. This unit treats cases such as measles, rabies, chicken pox, tetanus and chronic diarrhoea among others. At the time of the study, the Fevers Unit of the Korle Bu Teaching Hospital had about 6000 patients who were on ART. Tema General Hospital sees about $1500 \mathrm{HIV}+$ clients who are enrolled on ART. The Atua Government Hospital and St. Martins de Porres Hospital were the first PMTCT sites in Ghana. The Atua Government hospital and the St. Martins de Porres hospital have about 4800 and 4000 $\mathrm{HIV}+$ clients on ART respectively.

\section{Study participants}

The study participants comprised adult $\mathrm{HIV}+$ persons receiving ART at the Korle $\mathrm{Bu}$ Teaching Hospital, the Tema General Hospital, the Atua Government Hospital and the St. Martins de Porres Hospital. In addition, healthcare providers (i.e. Nurse Prescribers who manage the ART clinics) at the four study sites were interviewed.

\section{Sample size estimation and sampling}

The sample size for the survey component of the study was determined using Statcalc in Epi Info 2000 package. The exact number of HIV+ persons on ART who may be experiencing our primary outcome of interest (i.e. face barriers accessing ART) is unknown in the four study sites. Based on previous literature $[9,14]$ we estimated that $50 \%$ of the total number of $\mathrm{HIV}+$ persons on ART from the four study sites face one barrier or the other accessing ART. With an alpha of 0.05 and a statistical power of $90 \%, 434$ clients were computed as the minimum sample needed to assess the barriers HIV+ persons face accessing ART from the four treatment centres. To account for non-response and errors in data recording, this sample size was further increased by $20 \%$. The final sample size was thus $434+87=521$. However, being part of a larger study with an overall sample size of 540, all of the 540 PLH were used for this analysis.

Prior to sampling, the probability proportional to size weighting procedure was employed in the allotment of the HIV+ persons to the four study sites. Study participants were selected using systematic random sampling procedures. To do this, the master list of ART clients at each facility served as the site-specific sampling frame. The sampling interval ( $\mathrm{n}$ ) for each site was derived by dividing the total number of participants on the register by the required sample at each site.

For the qualitative component of the study, we purposively selected four ART In-charges (one each from the four study sites) for in-depth interviewing. These ART In-charges are healthcare providers (usually Nurse Prescribers) who manage the ART clinics at their respective hospitals. Therefore, not only were they knowledgeable in the workings of ART, but also they knew most of the HIV+ persons who were on ART in their respective clinics.

\section{Study instruments}

For the survey component of the study, questionnaires were the data collection instruments. The questionnaire had closed-ended questions as well as open-ended questions. The questionnaires were designed to elicit information on the various aspects of ART, including the socio-demographic characteristics of ART clients, desire and motivation to be on ART and barriers encountered in accessing ART. Apriori identified potential barriers to accessing ART, which formed part of the questionnaire, included periodic shortages of ARVs, cost of ARVs, side effects associated with ARVs, and perceived efficacy of alternative medications.

For the in-depth interviews with the four ART Incharges, an open-ended thematic topic guide was designed and used as the data collection instrument. The instrument was designed to ensure that similar themes and questions were covered in each interview. The instrument however had built-in flexibility that allowed for any pertinent but unexpected issues that arose during the individual interview process to be further probed. The instruments focused on exploring nurse priscribers' perspectives on $\mathrm{HIV}+$ persons' motivations for staying on ART, the nature of barriers encountered in accessing ART and how these barriers affected access to ART.

To ensure reliability, the study instruments were pretested on HIV+ persons on ART who were not selected for the actual study. The needed corrections and validations were done prior to the actual data collection. 


\section{Data collection}

The total number of respondents needed from a particular study site was interviewed between May 5 - June 302014. With the help of the ART Programme In-Charges, eligible study participants were identified and interviewed using paper-based questionnaires and topic guides. Interviews were conducted by 8 research assistants (RAs), and supervised by the PI. Typically, each questionnaire interview session took approximately $40 \mathrm{~min}$, and participant's responses to questions were recorded on questionnaires. In-depth interviews however lasted 40 - $60 \mathrm{~min}$, and the discussions were audio tape-recorded. In addition to conducting interviews, the RAs also reviewed participants' hospital records and relevant data were extracted.

The RAs were recruited from the University of Ghana's School of Public Health based on experience of conducting surveys and in-depth interviews as well as knowledge of the local area. They were all trained. Training entailed introduction to the study objectives, goals, methods and expected outcomes. There were extensive role-plays to ensure accuracy during data collection.

\section{Data management and analysis}

Data were reviewed daily for inconsistencies or omissions and problems with data completion addressed. Data collectors reviewed all completed data collection forms and corrected any errors or inconsistencies before hand-delivering them, along with their accompanying consent forms to field supervisors. Supervisors also reviewed the forms for accuracy, consistency, and completion. Once the data collection forms were considered complete, they were securely delivered to the principal investigator's office where they were kept in locked filing cabinets. All quantitative survey data were doubly entered into pre-programmed data screens designed in CSPro (Census and Survey Processing System) and doubly entered at a centralised location at the PI's institution. Data were exported to IBM SPSS Statistics, version 20, for consistency checks and validation. Cleaned and validated data sets were analysed using IBM SPSS Statistics. Analyses of survey data were descriptive; we used univariate analysis to generate descriptive tabulations for key variables from the survey.

For the qualitative data, audio tape recordings of indepth interviews were transcribed and the data were thematically analysed. Results from the survey and in-depth interviews were then brought together to illuminate the barriers HIV+ persons face accessing ART in Ghana.

\section{Results}

\section{Characteristic of study participants}

A total of 540 questionnaires were returned after the survey. Our unit of analysis is therefore 540. Table 1 shows the characteristics of the 540 ART clients who completed the survey. The mean age of the study participants was 42.3; age ranged from 18 to 65 years. Majority $(74.1 \%)$ of the participants were females.

The majority (42.9\%) of the participants were also married. Christians constituted $89.8 \%$ of the total sample, while $20.1 \%$ of the participants had no formal education. Also, majority (66.4\%) of the participants were selfemployed farmers. Except $7.4 \%$ of the participants who did not know how long they have been on ART, the length of time most participants reported being on ART ranged from 1 month to more than 11 years.

\section{Desire and motivation to be on ART}

Before examining the barriers PLH face accessing ART, we first investigated participants' desire and motivation to be on ART. Results from the survey suggest that all $(100 \%)$ the HIV+ persons interviewed were already linked to ART. Findings from qualitative open-ended questions embedded in the survey reveal a number of reasons why all participants desire to be on ART. These range from beliefs that ART will suppress the HIV virus, desire to maintain good health and prolong life, and desire not to infect unborn children, to desire to avoid death as well as desire to become a good therapeutic citizen (abide by doctors' advice). One female participant for example said: 'I want to be on ART because the ART will suppress the $H I V$ virus. This will help me maintain good health and prolong my life'. One male participant also said: 'I want to be on ART...I take the drugs because I do not want to die early. I take the drug to prolong my life so as to be able to look after my children'. One other female participant related why she was on ART and why she wants to be on it: 'Without ART, I would have been dead by now. It keeps me alive. That is why I want to be on it'. Another female participant said: 'We are asked at the counseling session to take our drugs...to take only the doctor's medicine. I do not want to disobey the doctor'. One male participant also said: 'I am on ART because I do not want to infect my unborn child'.

Indeed, interviews with ART Programme In-charges corroborated the accounts HIV+ persons gave. The ART Programme In-Charge at the ART clinic at Korle $\mathrm{Bu}$ hospital makes the point like this:

'I think they [referring to ART clients] want to be on ART because they do not want to joke with their lives. They value their lives and some of them too when they started coming to the ART clinic, the way they felt, the way they were sick and how they have improved have made them believe that indeed the ARVs work'.

The ART Programme In-Charge of the ART clinic at Atua government hospital shared similar views: 
Table 1 Characteristic of study participants ( $n=540$ unless indicated otherwise)

\begin{tabular}{|c|c|c|}
\hline Characteristic & Frequency & Percent \\
\hline \multicolumn{3}{|l|}{ Study site } \\
\hline Atua Government Hospital & 146 & 27.0 \\
\hline St Martin's Martins de Porres Hospital & 148 & 27.4 \\
\hline Tema General Hospital & 93 & 17.2 \\
\hline Fevers Unit, Korle Bu Teaching Hospital & 153 & 28.3 \\
\hline \multicolumn{3}{|l|}{ Region } \\
\hline Greater Accra Region & 246 & 45.6 \\
\hline Eastern Region & 294 & 54.4 \\
\hline \multicolumn{3}{|l|}{ Place of residence } \\
\hline Urban & 275 & 50.9 \\
\hline Rural & 265 & 49.1 \\
\hline \multicolumn{3}{|l|}{ Sex of respondent } \\
\hline Male & 140 & 25.9 \\
\hline Female & 400 & 74.1 \\
\hline \multicolumn{3}{|l|}{ Marital status of respondent } \\
\hline Single & 82 & 15.2 \\
\hline Married & 231 & 42.9 \\
\hline Divorced/Separated & 78 & 14.5 \\
\hline Widowed & 108 & 20.0 \\
\hline Cohabiting & 40 & 7.4 \\
\hline \multicolumn{3}{|l|}{ Religious affiliation of respondent } \\
\hline Not religious & 10 & 1.9 \\
\hline Christian & 485 & 89.8 \\
\hline Muslim & 43 & 7.9 \\
\hline Traditionalist & 2 & .4 \\
\hline \multicolumn{3}{|l|}{ Level of education } \\
\hline No formal education & 109 & 20.1 \\
\hline Primary & 123 & 22.9 \\
\hline$J H S$ & 170 & 31.4 \\
\hline SHS/Nocational & 102 & 18.9 \\
\hline Postsecondary /Tertiary & 36 & 6.7 \\
\hline \multicolumn{3}{|l|}{ Current Occupation } \\
\hline Unemployed & 107 & 21.0 \\
\hline Self-employed Farmer & 338 & 66.4 \\
\hline Formal sector employment & 9 & 1.8 \\
\hline Other & 55 & 10.8 \\
\hline Total & 509 & 100.0 \\
\hline \multicolumn{3}{|l|}{$\mathrm{Age}^{\mathrm{a}}$} \\
\hline $18-19$ & 5 & .9 \\
\hline $20-24$ & 12 & 2.2 \\
\hline $25-35$ & 126 & 23.3 \\
\hline $36-60$ & 374 & 69.3 \\
\hline $61+$ & 23 & 4.3 \\
\hline
\end{tabular}

Table 1 Characteristic of study participants ( $n=540$ unless indicated otherwise) (Continued)

\begin{tabular}{lll}
\hline HIV Disease State & & \\
HIV positive with no AIDS & 365 & 67.6 \\
HIV positive with AIDS & 175 & 32.4 \\
Number of years on ART & & \\
Don't know & 40 & 7.4 \\
$<1$ & 47 & 8.7 \\
$1-3$ & 171 & 31.7 \\
$4-6$ & 152 & 28.1 \\
$7-10$ & 117 & 21.7 \\
11 and above & 13 & 2.5 \\
CD4 Cell Count, median (range) & $373(2-1663.0)$ \\
Total & 540 & 100 \\
\hline
\end{tabular}

${ }^{a}$ Mean age is 42.3 ; age ranged from 18 to 65 years

I think many of our clients are on ART and do want to be on ART because they have realised the dangers of not being on ART. Most of them have realised that they can lead normal lives and be able to have children who are HIV-free. So they are very motivated to come for treatment'.

Most of the narrative accounts that both the HIV+ persons and ART Programme In-charges gave suggested that most ART clients in the four study sites not only recognise the dangers of not being on ART, but they also recognise the benefits of being on ART. It is therefore the recognition of dangers and benefits that co-mingled to motivate most participants to stay on ART.

\section{Barriers to accessing ART}

Despite the fact that all the participants in this study expressed a desire to receive and remain on ART, a number of barriers were reported as hindering access to ART. Table 2 shows a tabulation of responses to three questions that asked participants to indicate three barriers (in order of priority) they face accessing ART. Seven main first priority barriers were reported by $63.3 \%$ of all the study participants. These were delays associated with receiving care from treatment centres (10.9\%), long distance to treatment centres $(1.1 \%)$, high financial costs associated with accessing and receiving ART (12.6\%), job insecurity arising from regular leave of absence to receive ART (2\%), shortage of drugs and other commodities (13.3\%), fear of side effects of taking ARVs (4.8\%), and stigma (1.3\%).

The percentage of participants reporting delays associated with receiving care from treatment centres, long distance to treatment centres, high financial costs associated with accessing and receiving ART, job insecurity arising from regular leave of absence to receive ART, 
Table 2 Barriers encountered in accessing ART

\begin{tabular}{|c|c|c|c|c|c|c|c|}
\hline \multirow[t]{2}{*}{ Barrier } & \multicolumn{2}{|c|}{$1^{\text {st }}$ Barrier } & \multicolumn{2}{|c|}{$2^{\text {nd }}$ Barrier } & \multicolumn{2}{|c|}{$3^{\text {rd }}$ Barrier } & \multirow{2}{*}{$\begin{array}{l}\text { Total } \\
N\end{array}$} \\
\hline & Freq & $\%$ & Freq & $\%$ & Freq & $\%$ & \\
\hline Delay before care is received & 59 & 10.9 & 35 & 6.5 & 9 & 1.7 & 103 \\
\hline Long distance to treatment centres & 6 & 1.1 & 24 & 4.5 & 11 & 2 & 41 \\
\hline Financial challenges & 68 & 12.6 & 24 & 4.4 & 19 & 3.5 & 111 \\
\hline Job insecurity & 14 & 2.6 & 7 & 1.3 & 5 & 0.9 & 26 \\
\hline No challenge & 198 & 36.7 & 350 & 64.8 & 418 & 77.4 & 966 \\
\hline Shortage of drugs and other commodities & 72 & 13.3 & 34 & 6.3 & 12 & 2.2 & 118 \\
\hline Fear of side effects & 26 & 4.8 & 8 & 1.5 & 2 & 0.4 & 36 \\
\hline Stigmatisation & 7 & 1.3 & 6 & 1.1 & 3 & 0.6 & 16 \\
\hline Total & 540 & 100 & 540 & 100 & 540 & 100 & 1620 \\
\hline
\end{tabular}

shortage of drugs and other commodities, fear of side effects of taking ARVs, and stigma as second priority barriers however decreased to $6.5,4.5,4.4,1.3,6.3,1.5$, and $1.1 \%$ respectively. These percentages, respectively, further decreased to $1.7,2,3.5,0.9,2.2,0.4$, and $0.6 \%$ when participants were asked to indicate their third priority barrier. Crucially, $36.7 \%$ of the participants reported that they did not face any barriers accessing ART when they were asked to mention their first priority barrier. This percentage, respectively, increased to 64.8 and $77.4 \%$ when participants were asked to indicate their second and third priority barriers.

Responses from the qualitative open-ended questions embedded in the survey tools and the four ART Programme In-charges illuminated the nature of some of the barriers and the ways in which these barriers acted to hinder access to ART for different categories of $\mathrm{HIV}+$ persons. In relation to the cost associated with ART for example, many of the participants reported that although government has subsidised the costs of ARVs, the five Ghana cedis that they pay monthly to receive ARVs was still not affordable, especially for those who are not employed. Coupled with costs associated with transportation as well as opportunity costs of travelling to receive care, several participants, especially from rural areas, reported that they are sometimes deterred from seeking ART because of financial constraints. One female participant makes the point thus:

'I have challenges with paying for the drugs. We pay monthly five cedis for the drugs; though this is not much, I am unemployed and I do not have this amount all the time. Also, because I come from the village, I need money to pay for transportation. They will refuse to give me the drugs too if I do not have the money to pay. This is my number one challenge'.

Another female participant also related how delay associated with receiving care from ART clinics was an important barrier to ART access. 'My major problem is the long waiting time...sometimes we go early to the clinic but you will come home very late. This makes me feel reluctant to go sometimes'. Many of the participants felt that they spend too much time waiting for the needed services at each clinic visit. Delays at ART clinic were reported to come from three main sources, namely delay before folder is received, delay before seeing a doctor/counselor, and delay at the pharmacy where medicines are dispensed. These delays were particularly concerning for participants who are employed in the formal sector, and who often need permission to absent themselves from work in order to attend ART clinic sessions. As one participant said: 'My boss does not want me out of the factory for long during working hours'. Thus long hours of absence from work was reported to breed job insecurities as employers are more likely to replace workers who frequently demand leave of absence. Indeed, a number of participants made reference to HIV+ persons who had lost their jobs due partly to their HIV+ status, arising from regular requests for leave of absence to seek treatment.

Others also spoke about how regular shortages of drugs and other commodities such as nutritional supplements often serve as disincentive for visiting ART clinics. One male participant made the point like this:

\section{The problem I have encountered is that sometimes I will travel from my village to the clinic and they will say there is no medicine or they will give me small medicine and ask me to come the next week. You know it is not easy to travel all this long distance.}

Some participants also reported how fear of side effects and stigmatisation were major barriers to accessing ART. 'I experience some rashes on my skin which do not allow me to come for medicine. Participants who were on ART for a relatively shorter time period before this study, particularly reported side effects such as rashes. 
Several of the narratives here suggested that the physical manifestation of these side effects often triggered questions and suspicions from both family members and the general public. In relation to stigma, one participant said: 'My heart beats faster whenever it is time for me to go for ART...I am always afraid that I will meet someone I know at the clinic...you know the stigma'. Thus fear of being seen in an ART clinic by a known family member or friend and the fear that one maybe stigmatised acted as serious disincentives for $\mathrm{HIV}+$ persons to access and use ART services.

Results from in-depth interviews with the ART Programme In-charges largely supported a number of the barriers $\mathrm{HIV}+$ persons reported. For instance, the ART Programme In-Charge at the ART clinic at the St. Martins de Porres hospital noted that:

'Sometimes they [referring ART clients] are poor and they don't even have food to eat. How then can such people pay for the transport and the small fees that they are required to pay every month before receiving treatment?'

The ART Programme In-Charge at the ART clinic at Korle $\mathrm{Bu}$ hospital did not however think cost should be a hindrance to accessing ART:

'HIV treatment is basically free here. They [referring to ART clients] don't pay for consultation. The medicines, they pay a token of GHS 5 a month. The medicine itself is free but the GHS 5 a month is to help the administrative work and even with that, now they've introduced health insurance into it, so those who have health insurance, it covers that GHS 5 so they end up not paying and if you come and you don't have health insurance and GHS 5, you are still given your medicine but the medicine you don't pay for it. So I don't think cost should be a problem'.

This participant however acknowledged that periodic shortage of drugs and basic consumables was a challenge.

'At times there is shortage of drugs and when there is shortage of drugs, it becomes a headache for us because we don't know what is going to happen to the patients. We ourselves when there is shortage of drugs, test kits and other things, it is very difficult for us to work'.

\section{Discussion}

This paper adds to the small but growing number of empirical studies in the Ghanaian context that have attempted to explore the barriers $\mathrm{HIV}+$ persons face in accessing ART. The paper reveals a number of findings that should not be overlooked. The majority of our study participants were either self-employed farmers (66.4\%) or unemployed $(21 \%)$. Previous literature has highlighted the causally-causative nature of the relationship between poverty, unemployment and HIV/AIDS infection: that poverty and unemployment could expose individuals to risks of HIV/AIDS infection just as being HIV/AIDS positive could trigger poverty and unemployment [23]. While our study did not set out to investigate this relationship, in-depth interviews with some participants in this study suggested that in some cases, self-employment and unemployment were themselves the product of HIV + persons losing their jobs in other viable sectors of the economy due partly to their $\mathrm{HIV}+$ status. Selfemployment in farming is an important livelihood activity in Ghana; but evidence from our qualitative in-depth interviews suggested that most of the study participants were subsistent farmers or were poor. This could potentially limit the ability of such persons to generate and accumulate sufficient stock of resources to be able to access ART as well as meet their nutritional requirements. This would suggest the need for targeted social and economic safety net interventions such as conditional cash transfer programmes and free or subsidised nutritional supplementation interventions to support unemployed and poor HIV+ persons to pay for HIV treatment costs and meet their daily nutritional requirements. In the context of Ghana more specifically, it might be beneficial to include unemployed and poor PLH in current social protection programmes such as the Livelihoods Empowerment Against Poverty (LEAP) programme.

Findings also revealed that $74 \%$ of the study's participants were women. This statistic, we believe, is not the result of sampling bias as both our examination of ART clients' hospital records and discussions with ART Programmes In-charges suggested that, indeed, more women than men are currently on ART in Ghana. We believe this situation could potentially be explained by a number of factors. Generally, the biological make-up of women makes them more susceptible to HIV infection than men. HIV is more readily transmitted from men to women than women to men, with explanations related to the larger surface area of the vagina and frequency of tears during sexual intercourse [24]. While this biological vulnerability is indisputable, it has been recognised that stressful factors such as social and economic vulnerability of women in Africa often drive and sustain patterns of unsafe sexual practices that place women at risk of HIV [25]. This may partly explain why more women are currently infected with HIV than men both in Ghana and across the Sub-Saharan Africa region [25, 26]. This may in turn explain why more women than men are on ART. Also, improved screening of women for HIV during pregnancy in Ghana has meant that many more $\mathrm{HIV}+$ women are detected and enrolled on ART than 
men. Coupled with current levels of low counseling and testing among men [27], it is plausible to think that more women would dominate the list of ART clients. In addition, HIV+ men have been found elsewhere to be less willing to enroll on ART programmes partly because of masculinity and gender role/identity conflicts and partly because of shame and stigma [28, 29]. It is therefore possible that many HIV+ men in Ghana may be abstaining from ART programmes for similar reasons. In this regard, there may be the need for further research to understand why more women than men are receiving HIV treatment at ART clinics in Ghana. In the meantime, our findings here would suggest the need for interventions to also screen men as well as reach out to HIV+ men with available treatments.

All (100\%) the HIV-positive persons interviewed in this study were linked to ART. Consistent with previous research elsewhere [29], we found that the reasons why participants were on ART ranged from beliefs that ART will suppress the HIV virus, desire to maintain good health and prolong life, and desire not to infect unborn children, to desire both to avoid death, and to become good therapeutic citizens (abide by doctors' advice). That all participants recognised the benefits of ART and wanted to be on ART clearly presents a golden opportunity for the government of Ghana, the Ghana Health Service, healthcare providers and international partners to build on this enthusiasm and initiate and/ or scale-up programmatic and treatment interventions to reach all HIV+ persons who need treatment. This could include the provision of better and expanded screening services especially to rural and hard-to-rich populations, the creation of more HIV treatment centres, and the resourcing of such centres with trained professional caregivers and essential commodities. Of course, given the limited financial and human resources that are usually dedicated to healthcare provisioning in Ghana, implementing these recommendations can put additional pressure on the healthcare system. However, the benefits of this additional investment could be enormous as modest but effective ART coverage has been shown to substantially reduce morbidity and mortality related to HIV/AIDS infection as well as HIV transmission risks [1-5].

Despite the fact that all the HIV-positive persons sampled in this study were already linked to ART, $63.3 \%$ of them reported experiencing at least one major barrier in accessing ART. While the $36.7 \%$ who reported experiencing no challenge in accessing HIV treatment services is an encouraging sign that Ghana is probably doing some things right, the fact that majority of the ART clients are experiencing challenges in accessing care must be cause for concern. Among the first most important barriers the participants in this study reported were delays associated with receiving care from treatment centres
(10.9\%), long distance to treatment centres (1.1\%), high financial costs associated with accessing and receiving ART (12.6\%), job insecurity arising from regular leave of absence to receive ART (2\%), shortage of drugs and other commodities (13.3\%), fear of side effects of taking ARVs (4.8\%), and stigma (1.3\%). These barriers are very similar to what has been documented in other previous studies elsewhere [7, 14, 17-21] and in Ghana more specifically $[9,11]$.

A substantial number of participants (10.9\%) reported delays associated with receiving care from treatment centres as a major barrier. Delays came from long waiting times before care was received. This long waiting time is often the result of limited numbers of trained healthcare personnel and ART centres. Compounding the problem is the fact that only specific days in a month are dedicated to all ART clients to receive care. The lack of individualised booking system to receive care has meant that large numbers of patients are brought to treatment centres to receive care at the same time. Very often, the limited healthcare staff at most of the treatment centres is not able to promptly provide care to all clients, leading to delays. As other researchers have found, most clinics are under-resourced with long waiting queues - all of which challenge the success in retaining HIV patients in chronic care $[5,29,30]$. While these delays are part of the realities of the healthcare delivery systems in most resource limited settings and may therefore not be unique to ART clinics, they are a major disincentive for PLH to access ART. As a number of our research participants reported, these delays are very concerning for ART clients who are employed in the formal sector, and who often require permission to absent themselves from work in order to attend ART clinic sessions. Therefore, spending long hours at treatment centres instead of work places could offer employers reasons to replace such employees. Our findings here would therefore suggest the need for interventions to address these delays and other related barriers (see Table 3 ).

In addition to increasing the number of caregivers at ART clinics, it might be helpful to design and institute an individualised booking system whereby individual clients could choose different days during the month to attend ART clinics. This could reduce the numbers of ART clients seeking care at any particular point in time to manageable sizes. This may reduce the overcrowding and long waiting time that are currently associated with ART clinics. The recommendations here are supported by previous evidence from elsewhere that suggest that increasing ART centres and health workforce can reduce delays that are associated with receiving ART [12].

Several of the participants (12.6\%) also reported cost as a barrier to accessing care. While the current direct 
Table 3 Potential ways to address barriers encountered in accessing ART

\begin{tabular}{ll}
\hline Barrier & Possible way(s) to address barrier \\
\hline Delay before care is received & - Establish more ART centres \\
& - Train more caregivers \\
& - Institute an individualised booking system so ART clients can choose different days \\
& to receive care \\
& - Establish more ART centres \\
& - Implement occasional outreach programmes to care for ART clients \\
& - Institute travel costs reimbursement schemes \\
& - Create family, community, and peer support groups \\
& - Establish targeted social and economic safety net interventions for HIV+ persons e.g. \\
& conditional cash transfer programmes \\
& - Include HIV+ persons, especially ART clients in LEAP programme \\
& - Create family, community, and peer support groups \\
& - Institute free/subsidised nutrition supplementation interventions \\
& - Institute travel costs reimbursement schemes \\
& - Allocate more financial resources, especially financial resources to ART \\
& - Prevent wastage in the use of drugs and other commodities \\
& - Reduce inefficiencies in management and use of medicines \\
& - Educate ART client on how to properly administer medications \\
Shortage of drugs and other commodities & - Educate ART clients on possible side effects of different treatment regimens and how to \\
& minimise potential side effects \\
Fear of side effects & - Educate public on HIV/AIDS using both print and electronic media, including social media \\
Stigmatisation & - Institute anti-stigma interventions using community based and led strategies
\end{tabular}

cost of ART in Ghana is relatively negligible, many HIV+ persons are still not able to afford to pay this cost and other additional indirect costs. This is partly because current approaches to providing care include multiple clinic visits, which are costly for the patient in terms of money and time. Consequently, patients who are poor and lack resources for transport might opt to not attend clinic. This could adversely affect adherence to treatment and may cause relapse. In addition to the inclusion of PLH in social and economic safety net programmes as we have suggested above, the institutionalisation of a travel costs reimbursement scheme might be useful. Elsewhere, similar schemes have been reported to enhance access to ART as well as increase ART adherence rates among HIV + persons [13]. In the context of Ghana, such a scheme could be used to reimburse travel costs for ART clients, especially those from rural areas who often travel long distances to access ART. Also, there is the need to generate social support for ART clients at the levels of peers, family and community. Such an intervention has been shown to greater improve access to ART and as well enhance adherence to ART [31]. In the context of Ghana, such social support interventions could be modelled along the lines of the directly observed treatment (DOTs) methods which have been successfully used in the treatment and management of tuberculosis (TB). As DOTs has successfully been used in Ghana in the context of TB, we believe a similar approach in the area of ART has the potential to succeed.

Shortage of drugs and other commodities was also reported as a major barrier to effective ART access. This indeed is one of the major challenges confronting effective HIV/AIDS treatment across low- and middle-income countries, and a number of researchers and policy documents have recently acknowledged it [4-7]. In the presence of shortage of ARVs and other essential consumables, the full benefits of ART may not be realised. This would suggest the need for more resources to be allocated to purchasing and stocking ART clinics with sufficient quantities of essential medicines and commodities. This should also be accompanied by strategies to prevent waste and inefficiencies in the management and use of medicines and essential commodities through such practices as over prescription and corruption (e.g. stealing or embezzlement of medicines from public ART clinics for personal profit). Indeed, there is evidence to suggest that countries that have made significant progress in rolling out ART and reducing HIV infection have done so with significant investment of both human and financial resources [12, 13, 32]. Such countries have also effectively prevented wastage, theft of medicines and corruption in the management of ART programmes [12, 13, 32].

Additional barriers that participants reported included fear of side effects of taking ARVs and stigma. We believe patient education on how to appropriately administer medications as well as possible side effects of different treatment regimen may help reduce both the side effects of drugs and the fear that some patients harbour. Similarly, continues public education and interventions to de-stigmatise HIV/AIDS and reduce stigma and discrimination against PLH may help 
increase uptake of ART. As previous studies have shown, both patient and public education can greatly improve adherence to ART by reducing anxieties about of side effects of ARVs as well as minimise stigma against HIV+ persons [13, 20, 32].

Taken together, the findings presented in this paper highlight an urgent need for interventions to address different individual level and structural barriers to ART access so as to optimise the full benefits of ART. The findings and the accompanying recommendations should however be read against the backdrop of certain limitations. The research reported in this paper was conducted at four ART clinics in southern Ghana. Therefore, the limitation of applying the findings in other parts of the country is acknowledged. This is more so because HIV+ persons are not a homogenous group, hence the perspectives of those interviewed in this study might be different from what pertains elsewhere in Ghana. In this regard, large-scale quantitative and qualitative studies might be required to provide a more holistic picture about the challenges HIV+ persons face in accessing ART services at the national or regional levels. Finally, there are a number of characteristics not captured in the baseline demographics but have been shown to be associated with access/ retention on ART. These include active illicit drug/ alcohol use, mental illness, homelessness, viral load, type of ART regimen prescribed and dosing, criminal justice history, domestic and/ or interpersonal violence. These limitations notwithstanding, important lessons can be drawn from the findings in this paper to inform policies and interventions that seek to promote greater access to HIV/AIDS treatment for HIV+ persons. In particular, the results of the study provide useful pointers for policymakers and healthcare providers within Ghana and across the world to participate in designing innovative interventions to redress the remaining barriers that PLH face in accessing needed treatment.

\section{Conclusions}

Results from this study indicate that a number of structural and individual level barriers still act, alone or in concert, to hinder HIV+ persons' access to ART in Ghana, even in situations where these services are available. Efforts to provide and scale-up ART to all HIV+ persons and ensure adherence must also be accompanied by interventions that address these remaining structural and individual level access barriers. Among other interventions (see Table 3), we recommend the institutionalisation of individual booking/appointment system of care, and a travel reimbursement scheme for ART clients, more investment to train more staff, purchase and stock ART clinics with essential drugs and commodities as well as patient and public education, to help address these challenges.

\section{Additional file}

Additional file 1: The Survey Questionnaire is included as an additional file. (DOCX 123 kb)

\section{Abbreviations}

AIDS: Acquired Immune deficiency Syndrome; ART: Antiretroviral therapy;

ARVs: Antiretroviral; CSPro: Census and Survey Processing System;

DOT: Directly observed treatment; GHS: Ghana cedis; HIV: Human

immunodeficiency virus; LEAP: Livelihoods empowerment against poverty;

PLHIV: Persons living with Human Immunodeficiency Virus; RAs: Research

assistants; SPSS: Statistical package for the social science; STI: Sexually

transmitted infection; TB: Tuberculosis; WHO: World Health Organization

\section{Acknowledgements}

To all the HIV-positive persons who voluntarily participated in the survey; to the management of the Fevers Unit of the Korle-Bu Teaching Hospital, the Tema General Hospital, the Atua Government Hospital, and the St Martin's de Porres Hospital, we are grateful.

\section{Availability of data and materials}

The authors agree that the dataset on which the conclusions of this manuscript rely be deposited in publicly available repositories. This dataset is published and is accessible from the link below. https://dataverse.harvard.edu/dataset.xhtml? persistentld=doi\%3A10.7910\%2FDVN\%2FN8YT10.

The file name of the dataset is: Manuscript_3_dataset.

We have, however, not included personal identifiers such as names, age, and sex, to preserve patients' privacy. Aside the data set, we have included the Survey Questionnaire as an Additional file 1.

\section{Funding}

The study was supported by the University of Ghana Research Fund administered and managed by the Office of Research, Innovation and Development under Grant Number URF/6/ILG-019/2012-2013. Grant Recipient: Dr. Amos K. Laar.

The funder however played no role in the design, data collection, analysis, interpretation of data, writing of the manuscript, and the decision to submit the manuscript for publication.

\section{Authors' contributions}

AKL conceived the study, discussed the idea with MYL and PAN and obtained inputs. Led by AKL, AK, MYL, PAN, AA, and MPKO contributed to the development of the study protocol for ethical clearance. MYL supervised data collection at the Korle-Bu Teaching Hospital, AKL supervised data collection at the other three hospitals. With inputs from JKG, AKL drafted the methods section of the paper. AL and JKG conducted the data analysis. $J K G, A K L$, and AA drafted different sections of the manuscript. All authors contributed to the interpretation of the data, read, and approved the final version of the manuscript.

\section{Authors' information}

Amos Laar has demonstrated research interests spanning HIV, maternal, infant, and young child nutrition. He has experience in planning, implementing and disseminating community-based research. He has been a Co-Investigator of ten successful research grants at the University of Ghana, and has published 32 articles in refereed journals.

Awewura Kwara is an Infectious Diseases Specialist, with training in Public Health and Tropical Medicine. He is an Associate Professor of Medicine at Warren Alpert Medical School of Brown University. His clinical and research interest is in management HIV and TB coinfection. His research in the area of TB and HIV treatment has made important contributions to international research efforts in the field of pharmacokinetics, pharmacogenetics and drug-drug interactions between antiretrovirals and anti-TB drugs.

Priscillia A. Nortey is a Lecturer at the Department of Epidemiology and Disease Control, School of Public Health, University of Ghana, Accra, Ghana. She is a clinical pharmacist worked most of her professional life in the public health delivery service of Ghana. In the last 10 years of her time in this service she was mostly involved in training of health personnel. She has been part of the teams involved in the development of several health management guidelines, notably guidelines for HIV and AIDS comprehensive 
care, pharmaceutical service, tuberculosis, malaria and training health personnel in the provision of these services. She has also been a core member of clinical team for renal transplant and scoliosis surgery.

Michael P.K. Okyerefo is a Senior Lecturer, Department of Sociology, University of Ghana. A trained sociologist with varied research interests, including a focus on the nexus of religion and a host of socio-economic, political, and health processes in contemporary Ghana, Dr. Okyerefo's research centres on two general areas of sociological inquiry, cultural sociology and sociology of religion. He is principal investigator in a research on Religious and Health Beliefs and Practices of Prayer Group members in Achimota Forest, Accra. Margaret Y. Lartey is a Professor of Medicine and has been working closely with HIV infected patients in the area of clinical management. In Ghana, she is the most experienced HIV Clinician managing the single largest clinic with 15,000 patients on roll and 6000 on antiretrovirals. She contributes actively to drawing of guidelines and policies on management of HIV infection and involved in the training of all cadres of health workers in HIV care as well as supervising and monitoring other sites.

Augustine Ankomah is a demographer with PhD in Applied Population Research. He is a Professor Population, Family and Reproductive Health at the Department of Population, Family and Reproductive Health, School of Public Health, University of Ghana. Prof. Ankomah has over 25 years experience in the teaching and practice of developing, implementing and evaluating evidence-based interventions in reproductive health, HIV prevention, family planning and other maternal, newborn and child health interventions. His current research interests are in John Kuumuori Ganle has a DPhil in Public Health with specialisation in reproductive, maternal and child health from the University of Oxford, United Kingdom. He is a lecturer in the Department of Population, Family and Reproductive Health, School of Public Health, University of Ghana. His research interests include maternal, newborn and child health; women's reproductive health; abortion and contraceptive behaviour; HIV/AIDS prevention and care; adolescent sexual and reproductive health; gender and health; and population and development in Ghana and Sub-Saharan Africa.

\section{Competing interests}

The authors declare that they have no competing interests.

\section{Consent for publication}

Participants' consent was also obtained for the purposes of publishing the results from the study. All the authors also consented to the study results to be published in the form presented in the final version of this manuscript.

\section{Ethics approval and consent to participate}

The study's protocol was reviewed and approved by the Ethical Review Committee of the Ghana Health Service (Protocol ID NO: GHS-ERC 03/11/13). Permission was granted from the facilities within which the study was conducted. These facilities were the St. Martins de Porres Hospital, Atua Government Hospital, the Tema General Hospital, and the Fevers Unit of the Korle Bu Teaching Hospital. Informed consent was obtained from all participants after the objectives and the methodology of the study were explained to them. In addition, participants were assured of privacy and confidentiality.

\section{Author details}

${ }^{1}$ Department of Population, Family and Reproductive Health, School of Public Health, University of Ghana, Legon, Accra, Ghana. ${ }^{2}$ Department of Medicine, University of Ghana School of Medicine \& Dentistry, University of Ghana, Legon, Accra, Ghana. ${ }^{3}$ Department of Medicine, Warren Alpert Medical School of Brown University, Providence, RI, USA. ${ }^{4}$ Department of Epidemiology and Disease Control, School of Public Health, University of Ghana, Legon, Accra, Ghana. ${ }^{5}$ Department of Sociology, University of Ghana, Legon, Accra, Ghana.

\section{Received: 28 December 2015 Accepted: 29 November 2016} Published online: 07 December 2016

\section{References}

1. Keiser O, Anastos K, Schechter M. Antiretroviral therapy in resource-limited settings 1996 to 2006: patient characteristics, treatment regimens and monitoring in sub-Saharan Africa, Asia and Latin America. Tropical Med Int Health. 2008;13:870-9.
2. Messeri P, Lee G, Abramson D, Aidala A, Chiasson M, Jessop D. Antiretroviral therapy and declining AIDS mortality in New York City. Med Care. 2003; 41(4):512-21.

3. van Sighem Al, van de Wiel MA, Ghani AC, Jambroes M, Reiss P, Gyssens IC Mortality and progression to AIDS after starting highly active antiretroviral therapy. AIDS. 2003;17(15):2227-36.

4. Addo-Atuah J, Gourley D, Gourley G, White-Means IS, Womeodu JR, Faris JR, Addo AN. Accessibility of antiretroviral therapy in Ghana: Convenience of access. SAHARA-J. 2012;9(2):74-87.

5. Mutevedzi PC, Newell M. The changing face of the HIV epidemic in subSaharan Africa. Trop Med Int Health. 2014;19(9):1015-28.

6. UNAIDS. Access to antiretroviral therapy in Africa: status report on progress towards the 2015 targets. Geneva, Switzerland: UNAIDS; 2015.

7. Kouanda S, Bocoum FY, Doulougou B, Bila B, Yaméogo M, Sanou MJ, Sawadogo M, Sondo B, Msellati P. Desclaux A. User fees and access to ARV treatment for persons living with HIV/AIDS: implementation and challenges in Burkina Faso, a limited-resource country. AIDS Care. 2010;22(9):1146-52.

8. Barnhart M, Shelton JD. ARVs: the next generation. Going boldly together to new frontiers of HIV treatment. Global Health Sci Pract. 2015;3(1):1-11.

9. Ohene S, Forson E. Care of patients on anti-retroviral therapy in Kumasi Metropolis. Ghana Med J. 2009:43(4):144-9.

10. Ghana Health service. National AIDS/STI Control Programme Ghana Annual Report 2007. Accra: Ghana Health Service; 2007.

11. Ampofo KW. Editorial commentary: Current status of HIV/AIDS treatment, care and support services in Ghana. Ghana Med J. 2009;43(4):142-3.

12. Rasschaert $F$, van Leemput $L$, Assefa $Y$, Schouten $E$, van Damme W. Tackling health workforce shortages during antiretroviral treatment scaleup_experiences from Ethiopia and Malawi. JAIDS. 2011;57:S109-12.

13. Harries $A D$, Zachariah $R$, Lawn SD, Rosen $S$. Strategies to improve patient retention on antiretroviral therapy in Sub-Saharan Africa. Tropical Med Int Health. 2010;15(s1):70-5

14. Seeling S, Mavhunga F, Thomas A, Adelberger B, Ulrichs T. Barriers to access to antiretroviral treatment for HIV-positive tuberculosis patients in Windhoek, Namibia. Int J Microbiol. 2014;3:268-75.

15. Denison JA, Koole O, Tsui S, Menten J, Torpey K, van Praag E, Bangsberg DR. Incomplete adherence among treatment-experienced adults on antiretroviral therapy in Tanzania, Uganda and Zambia. AIDS. 2015;29(3):361-71.

16. Meyers $T$, Moultrie $H$, Naidoo $K$, Cotton M, Eley B, Sherman G. Challenges to Pediatric HIV Care and Treatment in South Africa. J Infect Dis. 2007;196 Suppl 3:474-81.

17. Rao D, Kekwaletswe TC, Hosek S, Martinez J, Rodriguez F. Stigma and social barriers to medication adherence with urban youth living with HIV. AIDS Care. 2007;19(1):28-33.

18. Hardon AP, Akurut D, Comoro C, Ekezie C, Irunde HF, Gerrits T, Laing R. Hunger, waiting time and transport costs: time to confront challenges to ART adherence in Africa. AIDS Care. 2007;19(5):658-65.

19. Schackman BR, Gebo KA, Walensky RP, Losina E, Muccio T, Sax PE, Freedberg KA. The lifetime cost of current human immunodeficiency virus care in the United States. Med Care. 2006:44(11):990-7.

20. Max B, Sherer R. Management of the adverse effects of antiretroviral therapy and medication adherence. Clin Infect Dis. 2000;30(Supplement 2):S96-S116.

21. Sayles JN, Wong MD, Kinsler JJ, Martins D, Cunningham WE. The association of stigma with self-reported access to medical care and antiretroviral therapy adherence in persons living with HIV/AIDS. J Gen Intern Med. 2009;24(10):1101-8.

22. Blackstock O. Curing stigma - the limits of antiretroviral access. N Engl J Med. 2005;353(8):752.

23. de Waal A, Whiteside A. New variant famine: AIDS and food crisis in southern Africa. Lancet. 2003;362:1234-7.

24. Gray RH, Wawer MJ, Brookmeyer R, Sewankambo NK, Serwadda D, WabwireMangen F, Lutalo T, Li X, van Cott T, Quinn TC, Rakai Project Team. Probability of HIV-1 transmission per coital act in monogamous, heterosexual, HIV-1discordant couples in Rakai, Uganda. Lancet. 2001;357(9263):1149-53.

25. Jewkes R. HIV and women. In: Rohleder P, Swartz L, Kalichman SC, Simbayi LC, editors. HIV/AIDS in South Africa 25 years on: Psychosocial perspectives. New York: Springe; 2009. p. 27-40.

26. Oppong JR, Agyei-Mensah S. HIV/AIDS in West Africa: The case of Senegal, Ghana, and Nigeria. In: Kalipeni E, Craddock S, Oppong JR, Ghosh J, editors. HIV/AIDS in Africa: Beyond epidemiology. Oxford, UK: Blackwell; 2004. p. 70-82.

27. Yawson A, Appiah KL, Yawson OA, Bonsu G, Aluze-Ele S, Amanhyia NAKO, Lartey M, Adjei AA, Lawson LA, Beckwitt C, Kwara A, Flanigan T. Sex 
differences in perceived risk and testing experience of HIV in an urban fishing setting in Ghana. Int J Equity Health. 2014;13:109.

28. Lindegger G, Quayle M. Masculinities and HIV/ AIDS. In: Rohleder P, Swartz L, Kalichman SC, Simbayi LC, editors. HIV/AIDS in South Africa 25 years on: Psychosocial perspectives. New York: Springe; 2009. p. 41-54.

29. Skovdal M, Campbell C, Madanhire C, Mupambirey Z, Nyamukapa C, Gregson S. Masculinity as a barrier to men's use of HIV services in Zambia. Glob Health. 2011;7:1-14.

30. Thielman NM, Ostermann J, Whetten $\mathrm{K}$, Whetten $\mathrm{R}$, Itemba D, Maro V, CHAT Research Team. Reduced adherence to antiretroviral therapy among HIVInfected Tanzanians seeking cure from the Loliondo Healer. JAIDS. 2014; 65(3):e104-9.

31. DiMatteo MR. Social support and patient adherence to medical treatment: a meta-analysis. Health Psychol. 2004;23(2):207.

32. Reiter GS, Stewart KE, Wojtusik L, Hewitt R, Segal-Maurer, Johnson M, Fisher A, Zackin R, Masters III H, Bangsberg D. Elements of success in HIV clinical care: Multiple Interventions that promote adherence. Top HIV Med. 2003; 8(5):21-30.

Submit your next manuscript to BioMed Central and we will help you at every step:

- We accept pre-submission inquiries

- Our selector tool helps you to find the most relevant journal

- We provide round the clock customer support

- Convenient online submission

- Thorough peer review

- Inclusion in PubMed and all major indexing services

- Maximum visibility for your research

Submit your manuscript at www.biomedcentral.com/submit
Biomed Central 